\title{
HUBUNGAN SENAM YOGA PRENATAL DENGAN LAMANYA PROSES PERSALINAN KALA II PADA IBU BERSALIN DI BPS NENGAH SRINIATI KABUPATENMESUJI TAHUN 2017
}

\author{
Wike Sri Yohanna \\ DIV kebidanan/STIKes Aisyah Pringsewu Lampung, babeosake@gmail.com
}

\section{INFO ARTIKEL}

\section{Riwayat Artikel:}

Diterima: 11-01-2018

Disetujui: 29-01-2018

\section{Kata Kunci: \\ Yoga Pranatal, Proses Persalinan}

\begin{abstract}
Abstrak: Persalinan merupakan proses pergerakan keluarnya janin, plasenta, dan membrane dari dalam rahim melalui jalan lahir, proses persalinan di pengaruhi oleh 5 faktor yaitu power, passage, passenger, psikis dan penolong. Hasil prasurvey didapatkan pada bulan Januari - Desember tahun 2016 terdapat 15 ibu bersalin dimana yang mengalami persalinan lama terdapat 10 orang, yang mengalami persalinan cepat terdapat 5 Orang. Tujuan penelitian ini untuk mengetahui hubungan senam yoga prenatal dengan proses persalinan. Metode penelitian menggunakan penelitian kuantitatif dengan pendekatan cross sectional. Populasi penelitian yaitu seluruh ibu bersalin yang mengikuti yoga pranatal di BPS Nengah Sriniati sebanyak 71 orang dengan teknik total sampling. Analisa data menggunakan Chisquare. Hasil penelitian didapatkan distribusi frekuensi terdapat 21 (70,4\%) ibu hamil yang mengalami persalinan lama dan 57 (80,3\%) ibu yang rutin mengikuti senam yoga prenatal. Ada hubungan senam yoga prenatal terhadap proses persalinan pada ibu bersalin di BPS Nengah Sriniati Amd.Keb Kecamatan Way Serdang Kabupaten Mesuji dengan $p$-valu=0,003 sehingga $p-<\alpha=00,5$. Diharapkan tenaga kesehatan dapat meningkatkan penyuluhan kepada kelas ibu hamil khususnya tentang pentingnya senam yoga serta manfaat yang dapat dirasakan oleh ibu hamil yaitu, dapat mengurangi rasa takut ibu yang akan menghadapi persalinan, mengencangkan tubuh, mengendorkan otot - otot yang kaku serta memperlancar proses persalinan.
\end{abstract}

ABSTRAK

Abstract: Childbirth is the process of the movement of the discharge of the fetus and membrane from the embryo by the brith canac. The process of childbirth is influenced by 5 factors. That is passage, passanger, psikis and menolong. The result of prasurvey alotained in januari unril desember in the year 2016 there are matherhoad maternity which have longs labor experieves. Obtained 10 people which have kast labor experierves. Is 5 people. The goal of this research is to knows the correlations of gymnastics yoga and the process of labor.The metnode of this research is all the mothershood which have followed yoga prenatal in bps nengah sriniati as many 71 people with the technigue total sampling, data analye is used chi-sguare. The resuct of this research obtained 21 mather pregnant which have long labor experience and 57 the mother Which always kollowed gymnastics yoga prenatal, have a correlations bymnastics yoga prenatal toward the process of labor on the maternal in bps nengah sriniati kecamatan way serdang kabupaten Mesuji with $=p$-value $=$ 0,003 thcn $p-a=00,5$. Expected the worker of healthy can increase the illumination to the class mother pregnant especially the importance gymnastics yoga prenatal also the benefit of wich have felt by the mother pregnant can reduce the fear will face the labor, tighten the body, relaxes the muscles also speed up the prosess or labor Yoga prenatal,process of labor 


\section{A. LATAR BELAKANG}

Persalinan merupakan proses pergerakan keluarnya janin, plasenta, dan membrane dari dalam rahim melalui jalan lahir. Proses ini berawal dari pembukaan dan dilatasi serviks sebagai akibat kontraksi uterus dengan frekuensi, durasi, dan kekuatan yang teratur.mula mula kekuatan yang muncul kecil, kemudian terus meningkat sampai pada puncaknya pembukaan serviks lengkap hingga siap untuk pengeluaran janin dari rahim ibu (Asuhan Kebidanan Pada Masa Persalinan 2011).

Survei Demografi dan Kesehatan Indonesia (SDKI) tahun 2012 dalam Profil Kesehatan Indonesia (2014), dilaporkan dari seluruh persalinan, 64\% ibu tidak mengalami komplikasi selama persalinan, persalinan lama sebesar $31 \%$, perdarahan berlebihan sebesar $7 \%$, abortus $5 \%$, infeksi sebesar 5\%. Pada ibu yang melahirkan melalui bedah sesarea lebih cenderung melaporkan komplikasi 59\%, yang sebagian besar merupakan persalinan lama $42 \%$, perdarahan berlebihan $12 \%$ dan infeksi 10\% (SDKI 2012).

Data Dinas Kesehatan Provinsi Lampung tahun 2012 kejadian persalinan lama merupakan salah satu faktor penyebab meningkatnya AKI di Provinsi Lampung. Kejadian persalinan lama berkisar antara 1,8\%-2,6\% dari proses kelahiran. Pada tahun 2013 kejadian persalinan lama berkisar antara 3\%-5\% dari proses kelahiran (Dinkes Propinsi Lampung). Data yang diperoleh di Kabupaten Mesuji tahun 2015 tercatat 2.225 persalinan yang ditolong oleh tenaga kesehatan, dan pada tahun 2016 tercatat 2.969 persalinan yang di tolong oleh tenaga kesehatan. Sedangkan AKI pada tahun 2015 tercatat 2 orang meninggal disebabkan karena eklamsia, dan AKI pada tahun 2016 tercatat 10 orang meninggal dimana 2 orang meninggal karena eklamsi dan 8 orang meninggal disebabkan pendarahan dan faktor lainna (Dinkes Mesuji).

Faktor - faktor yang mempengaruhi proses persalinan adalah diantaranya faktor power (tenaga / kekuatan), faktor passage (jalan lahir), faktor passenger ( janin dan plasenta), faktor psikologi ibu, faktor penolong. Terdapat beberapa macam latihan fisik yang dapat membantu bumil memperoleh power yang baik sehingga memperlancar proses persalinan yaitu yoga antenatal. Yoga adalah cara yang baik untuk mempersiapkan persalinan karena teknik latihannya menitik beratkan pada pengendalian otot, teknik pernapasan, relaksasi, ketenangan pikiran yoga sangat berperan dalam mempersiapkan proses kelahiran ibu hamil dikarenakan perubahan fisik dan perubahan psikis yang dialaminya (Yuliarti, 2011).

\section{B. METODE PENELITIAN}

Jenis penelitian kuantitatif dengan pendekatan cross sectional. Populasi pada penelitian ini seluruh ibu bersalin Di BPS Nengah Sriniati yang berjumlah 71 orang ibu bersalin dengan teknik total sampling.

\section{HASIL DAN PEMBAHASAN}

\section{Lamanya Persalinan}

Tabel 1

Distribusi Frekuensi lamanya persalinan Di BPS Nengah Sriniati Amd.Keb KecamtanWay Serdang Kabupaten Mesuji Tahun 2016

\begin{tabular}{|c|l|c|c|}
\hline No & $\begin{array}{c}\text { Lamanya } \\
\text { persalinan }\end{array}$ & Frekuensi & Persentase \\
\hline 1 & Cepat & 50 & 29.6 \\
\hline 2 & Lama & 21 & 70.4 \\
\hline \multicolumn{2}{|}{ Jumlah } & 71 & 100.0 \\
\hline
\end{tabular}

Berdasarkan tabel 1 diketahui bahwa dari $71 \mathrm{ibu}$ hamil di BPS Nengah Sriniati Amd. Keb terdapat $21(70,4 \%)$ ibu hamil yang mengalami persalinan lama dan 50 (29,6 \%) ibu hamil yang mengalami persalinan cepat.

\section{Senam Yoga}

\section{Tabel 2}

Distribusi Frekuensi Senam Yoga Di BPS Nengah Sriniati Amd.Keb KecamtanWay Serdang Kabupaten Mesuji Tahun 2017

\begin{tabular}{|c|l|c|c|}
\hline No & Yoga Prenatal & Frekuensi & Presentasi \\
\hline 1 & Yoga & 57 & 80.3 \\
\hline 2 & Tidak senam yoga & 14 & 19.7 \\
\hline \multicolumn{2}{|c|}{ Jumlah } & 71 & 100.0 \\
\hline
\end{tabular}

Berdasarkan tabel 4.2 diketahui bahwa dari 71 ibu hamil di BPS Nengah Sriniati Amd. Keb terhadap $57(80,3 \%)$ ibu hamil yang mengikuti senam yoga dan 14 ( 19,7\%) ibu hamil yang tidak mengikuti senam yoga.

\section{Hubungan Senam Yoga Prenatal Dengan Lamanya Proses Persalian}

\section{Tabel 3}

Hubungan Senam Yoga Prenatal dengan Lamanya Proses Persalian Di BPS Nengah Sriniati Amd.Keb KecamatanWay Serdang Kabupaten Mesuji Tahun

\begin{tabular}{|c|c|c|c|c|c|c|c|c|}
\hline \multirow{4}{*}{$\begin{array}{c}\text { Senam } \\
\text { Yoga }\end{array}$} & \multicolumn{4}{|c|}{2017} & & & \multirow{3}{*}{$\begin{array}{c}\text { P- } \\
\text { Valu } \\
\text { e }\end{array}$} & \multirow{3}{*}{$\begin{array}{c}\text { OR } \\
95 \% \\
\text { CI }\end{array}$} \\
\hline & \multicolumn{4}{|c|}{ Proses Persalinan } & \multirow{2}{*}{\multicolumn{2}{|c|}{ Jumlah }} & & \\
\hline & \multicolumn{2}{|c|}{ Cepat } & \multicolumn{2}{|c|}{ Lama } & & & & \\
\hline & $\mathrm{N}$ & $\%$ & $\mathrm{~N}$ & $\%$ & $\mathrm{~N}$ & $\%$ & \multirow{4}{*}{0.003} & \multirow{4}{*}{$\begin{array}{c}6,750 \\
(1,905- \\
23,919)\end{array}$} \\
\hline Yoga & 45 & 78,9 & 12 & 21,1 & 57 & 100 & & \\
\hline $\begin{array}{l}\text { Tidak } \\
\text { Yoga }\end{array}$ & 9 & 64,3 & 5 & 35,7 & 14 & 100 & & \\
\hline Jumlah & 21 & 29,6 & 50 & 70,4 & 71 & 100 & & \\
\hline
\end{tabular}


Hasil uji statistic diperoleh nilai $p$-valu=0,003 sehingga $\mathrm{p}-<\alpha=0,05$ maka Ha diterima Ho di tolak, yang berati ada hubungan senam yoga prenatal terhadap lamanya persalinan pada ibu bersalin di BPS Nengah Sriniati Amd.Keb Kecamatan Way Serdang Kabupaten Mesuji tahun 2017.

\section{Lamanya Persalinan}

Berdasarkan tabel 1 diketahui bahwa dari $71 \mathrm{ibu}$ hamil Di BPS Nengah Sriniati Amd. Keb terhadap $21(70,4 \%)$ ibu hamil yang mengalami persalinan lama dan 50 (29,6 \%) ibu hamil yang mengalami persalinan cepat.

Sesuai dengan hasil penelitian oleh Dian Febri Sarwendah hubungan antara yoga prenatal dengan proses persalinan pada ibu bersalin di Bpm harti mustaqim sumowono kabupaten semarang (2014), diketahui bahwa terdapat $38(88,4 \%)$ ibu hamil yang mengalami proses persalinannya normal dan 5 ibu hamil yang proses persalinannya tidak normal.

Persalinan dan kelahiran normal adalah proses pengeluaran janin yang terjadi pada kehamilancukup bulan (37-42 minggu), lahir spontan dengan presentasi belakang kepala yang berlangsung dalam 18 jam, tanpa komplikasi baik dari ibu maupun pada janin ( Asuhan Kebidanan Pada Masa Persalinan 2011).

Kala I dimulai dari saat persalinan mulai sampai pembukaan lengkap $(10 \mathrm{~cm})$. Proses ini terbagi dalam 2 fase, fase laten( 8 jam) serviks membuka sampai $3 \mathrm{~cm}$ dan fase aktif (7 jam) serviks membuka dari 3 sampai $10 \mathrm{~cm}$.kontraksi lebih kuat dan sering selama fase aktif.

Kala II dimulai dari pembukaan lengkap (10 $\mathrm{cm})$ sampai bayi lahir proses ini biasanya berlangsung 2 jam pada primi dan 1 jam pada multi. Kala III di mulai segera setelah bayi lahir sampai lahirnya plasenta, yang berlangsung tidak lebih dari 30 menit.Kala IV dimulai dari saat nya plasenta sampai 2 jam pertama postpartum.

Menurut peneliti, di BPS Nengah Sriniati Amd.Keb ibu hamil persalinannya berlangsung cepat dikarenakan ibu aktif mengikuti senam yoga sedangkan pada ibu hamil yang tidak mengikuti senam yoga pada saat persalinan berlangsung lama dikarenakan merasa tidak nyaman, otot- otot kaki nya kaku dan jalan lahir nya tidak elastic sehingga persalinannya lama.

\section{Senam Yoga}

Berdasarkan tabel 4.2 diketahui bahwa dari 71 ibu hamil di BPS nengah sriniati Amd. Keb terhadap $57(80,3 \%)$ ibu hamil yang mengikuti senam yoga dan 14 ( $19,7 \%)$ ibu hamil yang tidak mengikuti senam yoga.

Sesuai dengan penelitian (Dian Febri Sarwendah 2014), diketahui bahwa dari 43 ibu hamil Di BPM Harti Mustaqim Suwono Kabupaten Semarang terhadap 8 (18.6\%) ibu hamil tidak rutin mengikuti senam yoga dan 35 (81.4\%) ibu hamil yang rutin mengikuti senam yoga.

Yoga adalah cara yang baik untuk mempersiapkan persalinan karena tehnik latihannya menitik beratkan pada pengendalian otot, tehnik pernafasan, relaksasi, ketenangan pikiran. Yoga berperan dalam mempersiapkan proses kelahiran ibu hamil dikarenakan perubahan fisik dan perubahan psikis yang dialaminya (Yuliarti, 2011).

Proses relaksasi akan sempurna dengan melakukan kontraksi dan relaksasi yang diperlukan untuk mengatasi ketegangan atau rasa sakit saat proses persalinan. Salah satu latihan menguatkan dan mempertahankan elastisitas adalah latihan menguatkan otot dasar panggul yang kegunaannya adalah melemaskan otot dasar panggul yang kuat dalam keadaan yang santai. Pada saat mengejan otot akan mengendur secara aktif sehingga kepala bayi akan keluar dengan mudah, dengan demikian akan memperlancar dalam proses persalinan (Irmawati, 2014).

Menurut peneliti, di BPS Nengah Sriniati Amd.Keb banyak yang aktif dalam melakukan senam yoga dan melatih menguasai teknik pernafasan yang berperan penting selama kehamilan dan proses persalinan. Kegunaan dari latihan dasar pernafasan yaitu melatih ketegangan, mempercepat sirkulasi darah serta mencukupi kebutuhan oksigen bagi ibu dan janinnya, sedangkan ibu hamil yang tidak melakukan senam yoga akan mengalami kram di kaki atau rasa kaku ditubuh yang dirasakan ibu hamil pada saat persalinan.

\section{Hubungan Senam Yoga Prenatal Dengan Lamanya Proses Persalian}

Hasil uji statistic diperoleh nilai $p-v a l u=0,003$ sehingga $\mathrm{p}-<\alpha=00,5$ aka Ha diterima Ho di tolak, yang berati ada Hubungan Senam Yoga Prenatal Terhadap proses Persalinan Pada Ibu Bersalin di BPS nengah sriniati Amd.Keb Kecamatan Way Serdang Kabupaten Mesuji tahun 2016 secara statistic $\mathrm{OR}=6,750$ yang berati ibu hamil yang mengikuti senam yoga proses persalinan nya lebih cepat sebanyak 6,750 di bandingkan ibu hamil yang tidak mengikuti Senam Yoga.

Sesuai peneliti yang dilakukan oleh Agustiana (2013), di BPS Prita Salatiga menunjukkan hasil penelitian bahwa ibu hamil yang mengikuti senam yoga rata rata 2-3 kali selama kehamilan dan lama persalinan kala II rata rata 43,88 menit, nilai $p$ value sebesar 0,0001 berati ada hubungan senam yoga ibu hamil dengan lama persalinan kala II pada ibu bersalin primigravida, dan nilai $\mathrm{r}=-0,0685$ yang berate senam juga memiliki kolerasi yang kuat dengan lama proses persalinan kala II dengan arah kolerasi negative dimana semakin banyak melakukan senam yoga semakin singkat waktu persalinan kala II. 
Hal ini juga sesuai dengan teori yang di kemukakan oleh wiadnyana (2008) yang menyatakan bahwa wanita hamil yang melakukan yoga secara rutin akan memperoleh keuntungan yaitu memperlancar proses persalinan, mengurangi section caesaria, dan mengurangi terjadinya gawat janin pada waktu persalinan.

Manfaat yoga yang tak kalah pentingnya yaitu memperkuat dan mempertahankan elastisitas otototot dinding perut, ligamentum, otot-otot dasar pangul dan otot paha bagian dalam, dengan demikian proses persalinan dapat dikuasai. Proses relaksasi akan sempurna dengan melakukan kontraksi dan relaksasi yang diperlukan untuk mengatasi ketegangan atau rasa sakit saat proses persalinan. Salah satu latihan menguatkan dan mempertahankan elastisitas adalah latihan menguatkan otot dasar panggul yang kegunaannya adalah melemaskan otot dasar panggul yang kuat dalam keadaan yang santai. Pada saat mengejan otot akan mengendur secara aktif sehingga kepala bayi akan keluar dengan mudah, dengan demikian akan memperlancar dalam proses persalinan (Irmawati, 2014).

Menurut peneliti, senam yoga berhubungan dengan proses persalinan dikarenakan senam yoga dapat menjaga elastisitas dan kekuatan ligament panggul, pinggul, dan otot kaki sehingga mengurangi rasa nyeri yang timbul saat persalinan serta memberikan ruang untuk jalan lahir, meningkatkan kenyamanan ibu pada 2 jam pasca salin dan mengurangi resiko persaliann lama.

\section{SIMPULAN DAN SARAN}

Berdasarkan pembahasan di atas, maka diperoleh beberapa kesimpulan sebagai berikut:

1. Diketahui distribusi frekuensi lamanya persalinan Di BPS Nengah Sriniati Amd. Keb Tahun 2016 sebanyak 21 (70,4\%) ibu hamil yang mengalami persalinan lama

2. Diketahui distribusi frekuensi senam yoga Di BPS Nengah Sriniati Amd. Keb Tahun 2016 sebanyak $57 \quad(80,3 \%)$ ibu hamil yang mengikuti senam yoga

3. Ada hubungan senam yoga prenatal dengan lamanya proses persalinan pada ibu bersalin Di BPS Nengah Sriniati Amd.Keb Kabupaten Mesuji Tahun 2016 dengan P- value 0,003 dan OR 6,750

Kemudian kami memberikan beberapa saran sebagai berikut:

1. BPS Nengah Sriniati

Dapat memberikan penyuluhan kepada kelas ibu hamil tentang penting nya senam yoga dengan alat peraga dan poster yang diberikan senam yoga. Ibu hamil mengerti tentang senam yoga bagi kesehatan tubuh ibu hamil, mengurangi rasa takut akan menghadapi persalinan, mengencangkan tubuh, mengendorkan otot otot yang kaku serta memperlancar proses persalinan. Kepada ibu hamil yang mempunyai saudara atau teman agar di dukung untuk mengikuti senam yoga.

2. STIKes Aisyah

Sebagai tambahan pustaka dan sebagai sarana untuk memperkarya ilmu dalam bidang kesehatan yang berkaitan dengan hubungan senam yoga prenatal terhadap proses persalinan pada ibu bersalin. Serta sebagai bahan referensi untuk penelitian selanjutnya.

3. Peneliti Selanjutnya

Dianjurkan hasil penelitian dapat digunakan selanjutnya sebagai pertimbangan jika hendak melakukan penelitian yang terkait dengan Senam Yoga Pranatal Dengan Lamanya Proses Persalinan Pada Ibu Bersalin.

\section{UCAPAN TERIMA KASIH}

Penulis mengucapkan terima kasih kepada ketua STIKes Putra Abadi Langkat yang telah memberikan dukungannya, terima kasih pada LPPM STIKes Putra Abadi Langkat yang telah mendanai penelitian ini dan terima kasih kepada bapak kepala desa Mangga yang telah memberi ijin untuk meneliti di daerahnya.

\section{DAFTAR RUJUKAN}

Widya, Panduan Dasar Yoga, Jakarta, 2015.

Rohani, Marisah, Asuhan Kebidanan Pada Masa Persalinan, Salemba Medika, Jakarta, 2011.

Elisabeth, Asuhan Kebidanan Persalinan Dan BBL, Pustakabarupress,Yogyakarta, 2015

Ari Sulistiawati, Asuhan Kebidanan Ibu Bersalin Pada Ibu Bersalin,Salemba Medika, Jakarta, 2012.

Notoatmodjo, Soekidjo, Metode Penelitian Kesehatan( Edisi Revisi), Rineka Cipta, Jakarta, 2010.

Islafatum, Nor, The Magic Movements Of Yoga, Trans Idea Publishing, Yogyakarta, 2014.

Widya, Setta, Yoga, Jakarta, 2015.

Sumantri, Arif, Metode Penelitian Kesehatan, Prenada Media Group, Jakarta, 2011.

Shindu, Pujiastuti, Yoga Untuk Kehamilan Sehat Bahagia Dan Penuh Makna, Bandung, 2014.

\section{PROFIL PENULIS UTAMA}

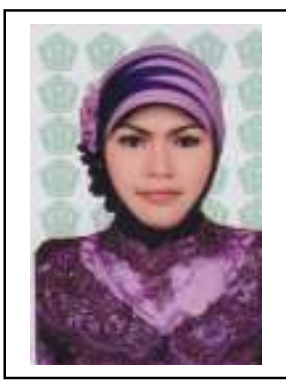

$$
\begin{aligned}
& \text { Nama : Wike Sri Yohanna, SST., M.kes } \\
& \text { TTL : Kerinci / } 8 \text { januari } 1985 \\
& \text { Institusi : STIKes Aisyah Pringsewu Lampung } \\
& \text { Contact : } 085279181181 \\
& \text { Email : babeosake@yahoo.com } \\
& \text { Riwayat Pendidikan: } \\
& \text { 1. Akademi Kebidanan Wira Buana Metro } \\
& \text { Lampung ( } 2003-2006) \\
& \text { 2. Diploma IV Kebidanana Universitas } \\
& \text { Malahayati Lampung (2011 - 2012) } \\
& \text { 3. Magister Kesehatan Universitas } \\
& \quad \text { Malahayati lampung ( } 2012-2014)
\end{aligned}
$$

